\title{
Role model: Carolyn Chew-Graham
}

\section{The professor of general practice research at Keele University and GP in Manchester, tells Adrian O'Dowd about her commitments to her specialty and medical education}

\section{Adrian O'Dowd}

London, UK

To Carolyn Chew-Graham, being a doctor is not just about working with patients and their families, but also supporting the next generation of doctors to fulfil their potential.

She qualified from the University of Manchester medical school in 1984 after deciding on medicine as a career for personal reasons. "It was related to the death of my father when I was 14 ," she says. "I felt I wanted to be involved in improving care for people, particularly older people and their families."

Her first job was at Manchester Royal Infirmary, but general practice was the field she was drawn to. "What appealed most was the breadth of input into people's lives from cradle to grave, being a witness to and sharing people's experiences, supporting them at critical and difficult times of their life, and then seeing them come out the other side," she says.

Chew-Graham worked in an inner city GP practice in Manchester for 10 years before joining another practice in the suburb of Chorlton. There she has specific responsibilities for older people and mental health, patient and public involvement, and teaching medical students. She also manages research activities in the practice, which is part of the Royal College of General Practitioners' Research Ready scheme. ${ }^{1}$

Nearly 25 years of working in general practice has taught her many things, Chew-Graham says. "What hit me when I was a GP trainee was the fact that there are factors in people's lives which are bigger determinants of their health, wellbeing, and illness than medicine will ever be.

"When I was a trainee, for the first six months I felt impotent. I worked in inner city Manchester and was upset by the poverty I saw, the complexity of people's lives and the fact that I could do very little in a 10 minute consultation.

"It was only when I was halfway through training that my excellent trainer Carl Whitehouse helped me see that even small impacts on people's lives did make a difference and that a GP can personally support them through difficult times."

Chew-Graham believes part of a doctors' role is to teach. "We teach patients during consultations where we give information and advice, checking out understanding, and helping patients make decisions," she says.
"In the same way, when you teach medical students, you find out where they're at and then negotiate a path together.

"Having medical students in my practice is one of the most rewarding things I do because you can see them develop over the time that they come into general practice. They go from thinking about single diseases to thinking about whole people with a complex mixture of diseases."

Chew-Graham currently spends a day a week working in general practice and the rest of her time at Keele University conducting research and supporting academic GP trainees and non-clinicians.

Her advice to medical students is direct and encouraging, "Make the most of opportunities. Keep an open mind when consulting, think about the patient holistically, and offer a broad range of treatment options. Above all, look after yourself."

Nominated by Faraz Mugha

Carolyn Chew-Graham leads by example. She is an active GP partner in a bustling Manchester practice and also leads on teaching, research, and the patient participation group.

In addition to this, she champions general practice and primary care research, especially in mental health, and patient and public involvement and engagement.

As an academic GP, her supervision and mentoring of her trainees and students is widely noticed and commended. She is readily available and always supportive and encouraging. In a time where more high quality general practice and primary care research and scholarship is vital to the ongoing development and sustainability of the NHS, she is leading the way in nurturing the next generation of clinical academic general practice and primary care researchers.

Faraz Mughal is a GP and National Institute for Health Research in-practice fellow at the Research Institute for Primary Care and Health Sciences, Keele University

Nominate a role model: To nominate someone who has been a role mode during your medical career, send their name, job title, and the reason for your nomination to arimmer@bmj.com.

Royal College of General Practitioners. Research ready. www.rcgp.org.uk/clinical-andresearch/our-programmes/research-facilitation-and-support/research-ready-selfaccreditation.aspx.

Published by the BMJ Publishing Group Limited. For permission to use (where not already granted under a licence) please go to http://group.bmj.com/group/rights-licensing/ permissions 